\title{
Cardio-pulmonary parasitic nematodes affecting cats in Europe: unraveling the past, depicting the present, and predicting the future
}

\section{Donato Traversa* and Angela Di Cesare}

Faculty of Veterinary Medicine, University of Teramo, Teramo, Italy

\section{Edited by:}

Damer Blake, Royal Veterinary

College, UK

Reviewed by:

Matthew John Nolan, Royal Veterinary College, UK

Mark Fox, Royal Veterinary College,

UK

*Correspondence:

Donato Traversa, Faculty of Veterinary Medicine, University of Teramo,

Piazza Aldo Moro 45, Teramo 64100,

Italy

e-mail:dtraversa@unite.it
Various cardio-pulmonary parasitic nematodes infecting cats have recently been fascinating and stimulating the attention of the Academia, pharmaceutical companies, and veterinary practitioners. This is the case of the metastrongyloids: Aelurostrongylus abstrusus and Troglostrongylus brevior, the trichuroid: Capillaria aerophila (syn. Eucoleus aerophilus), and the filarioid: Dirofilaria immitis. Apparently, these parasites have been emerging in several European countries, thus, gaining an important role in feline parasitology and clinical practice. Under a practical standpoint, a sound knowledge of the biological, epidemiological, and clinical impact of cardio-respiratory parasitoses affecting cats, in addition to a potential risk of introduction, establishment, and spreading of "new" parasites in Europe is mandatory in order to understand the present and future impact for feline medicine and to address new strategies of control and treatment. The purpose of the present article is to review the current knowledge of heartworm and lungworm infections in cats, discussing and comparing past and present issues, and predicting possible future scenarios.

Keywords: Aelurostrongylus abstrusus, Troglostrongylus brevior, Capillaria aerophila, Dirofilaria immitis, cat, epidemiology

\section{INTRODUCTION}

Parasitic nematodes affecting the cardio-pulmonary system of pets have recently attracted the attention of the Academia, pharmaceutical companies, and veterinary practitioners. This new interest has been stimulated by their apparent emergence in several European countries along with a re-discovered major role in clinical practice due to their pathogenic potential and the challenges posed in their diagnosis and control (1-4).

In Europe, the metastrongyloid Aelurostrongylus abstrusus and the trichuroid Capillaria aerophila (syn. Eucoleus aerophilus) are the most important nematodes affecting the respiratory system in cats. Metastrongyloid lungworms ranked within the genus Troglostrongylus have been considered affiliated to only wild felids for quite a long time, yet, recent records have shown the occurrence of Troglostrongylus brevior in domestic cats living in Europe, though only in Spain and Italy (5-10).

The filarioid Dirofilaria immitis is a nematode, which primarily infects the heart and pulmonary arteries of dogs and other canids, but it can infect cats as well. Nonetheless, its occurrence in cats is limited by the innate resistance of this host and infections are recorded, especially in those animals living in hyper-endemic regions, with a proportion of about $10-25 \%$ of the infected canine population $(11,12)$.

In the last decade, different drivers have changed the epidemiological scenario in Europe for these nematodes and, interestingly, there is evidence that various factors have presently been changing the distribution of cat cardio-pulmonary parasites in both endemic areas and previously free regions.
Indeed, climate changes, modifications in vector seasonal dynamics, movements in animal populations, shipping of goods, destruction of wildlife habitats, journeys of pets with their owners, may all play a role in the rise of cardio-pulmonary parasitoses $(1,4)$.

The majority of heartworms and lungworms infecting cats have an indirect life cycle, as they require an intermediate host for their development. Several species of mosquitoes, where Culex pipiens pipiens is the most important, transmit $D$. immitis, while a plethora of terrestrial mollusks act as intermediate hosts for A. abstrusus (13-16). Moreover, some species of gastropods may be competent vectors of A. abstrusus and T. brevior at the same time $(17,18)$.

The occurrence of cardio-respiratory nematodes is mainly influenced by the availability of competent gastropods and culicids in a given area, and at the same time the biology and the epidemiology of vectors and transmitted parasites is influenced by different factors, e.g., environmental temperature and humidity.

Contrariwise, C. aerophila develops directly in the environment, even though earthworms have been hypothesized to be facultative or paratenic intermediate hosts $(13,19)$. Drivers influencing the occurrence of lung capillariosis are still unknown, but modifications in wildlife habitats is likely at the basis of a common pattern of transmission between wild reservoirs and cats, with a possible emergence in domestic animals (20). Interestingly, the same factor could also influence the epidemiology of metastrongyloids and filaroids affecting cats $(4,8)$.

While changes in the current dispersion of cat parasites might be spurred by extrinsic and intrinsic factors, it should also be 
elucidated whether an increasing attention to these parasites has led to higher frequencies of documented diagnoses and/or it has partially or totally contributed to this apparent emergence.

The present review aims at discussing the past and present epidemiological scenarios for cardio-respiratory nematodes affecting cats, with a critical analysis of those drivers able to influence their occurrence in European territories, either singly or synergistically. Furthermore, new possible situations that could be expected in the near future, if the present trend continues, are discussed.

\section{THE PAST AND THE PRESENT \\ CLIMATE CHANGES}

The development and survival of invertebrates transmitting nematodes is influenced by temperature, moisture, and water availability. Therefore, global warming is nowadays considered as a major factor potentially nurturing the dispersal and spread of pathogens transmitted by vectors $(1,21,22)$. Importantly, climate changes are also likely to have an impact on the development and transmission patterns of cardio-pulmonary parasites.

Population dynamics and seasonal activities of mosquitoes are highly sensitive to temperature and moisture and, additionally, the development of Dirofilaria larvae in the insects is also known to be temperature-dependent. As a consequence, the transmission of $D$. immitis to vertebrates depends on a suitable climate allowing the survival and reproduction of mosquitoes and the larval development in the vectors themselves (23-25).

Indeed, recent literature on D. immitis has described a trend in its geographic spread, in both endemic and areas previously free of infection [reviewed in Ref. (4)]. First, the increase in average temperatures has actually influenced the abundance of mosquitoes and their seasonal survival in many territories of Europe, while, at the same time having an impact on the occurrence of filarial infections $(2,21,26)$. Specifically, warmer temperatures may promote mosquito breeding and reduce their extrinsic incubation periods (25). Second, it is well known that environmental temperatures influence the development of larval $D$. immitis to the infective stage in the mosquitoes. The incubation of $D$. immitis larval stages from microfilariae to infective L3 in mosquitoes is influenced by temperature thresholds. At $30^{\circ} \mathrm{C}$, the development is completed in 8-9 days (e.g., in Aedes vexans, Aedes triseriatus, Aedes trivittatus, and Anopheles quadrimaculatus) increasing to $10-14$ days at $26^{\circ} \mathrm{C}$, 17 days at $22^{\circ} \mathrm{C}$, and 29 days at $18^{\circ} \mathrm{C}(23)$.

Different forecast models, using wide or local scale temperature data, have been developed to predict the occurrence and seasonality of Dirofilaria (2, 21, 26-29). These climate-based systems usually employ the concept of growing degree days (GDD), i.e., 18 days are necessary for the development of Dirofilaria infective larvae when the average temperature for the day is $1^{\circ} \mathrm{C}$ above the threshold temperature. These models were based on the following evidence: development of Dirofilaria do not proceed below a threshold of $14^{\circ} \mathrm{C}(23)$, a requirement of 130 GDD for the larvae to reach infectivity and the maximum life expectancy is 30 days for a vector mosquito $(27,28)$. Some years ago these models showed that due to the rise in average temperatures and climate changes, most of the European countries have become suitable for Dirofilaria transmission, with a lengthening in the duration of the filarial transmission season $(26,29)$. After $<10$ years, the most recent information demonstrates the establishment of new foci of dirofilariosis in pets and wildlife in Europe and an increased prevalence in regions that previously experienced only sporadic infections $(3,4)$. Indeed, the epidemiological profile of dirofilariosis has substantially changed over the last decade. Until 2001, cardio-pulmonary dirofilariosis was mainly found in southern European countries (e.g., Italy, Spain, and France), which are considered historically endemic/hyper-endemic countries (3). An expansion of D. immitis toward central and northern Europe (e.g., Russia, Hungary, Czech Republic, Slovakia, Croatia, Serbia) has been reported in the last years $(3,4)$. For instance, autochthonous cases of D. immitis infection in dogs were reported in Hungary in 2009 (30), in Slovakia in 2010 (31), and in Poland in 2012 (32) and, in 2014, D. immitis was detected for the first time in C. pipiens/torrentium mosquitoes in Germany (33). Additionally, veterinarians have recently reported different cases of cardio-pulmonary dirofilariosis in Germany (34).

A prevalence of microfilariaemic hosts (mainly dogs and foxes) and the presence of competent vectors raise the rate of infection in the mosquito population, which is directly related to the risk of animals and humans being infected. D. immitis infections in cats in Europe have been reported in Italy, France, and Portugal, with an increasing frequency in areas where the disease is endemic in dogs [reviewed in Ref. (35)]. As a key example, in Italy, the infection in cats has been traditionally diagnosed for a long time in northern Italy with a prevalence that goes from 9 to $27 \%$ in the hyperendemic area of the Po River valley (36). In a recent study carried out in northern Italy, the prevalence of feline heartworm disease has been estimated as $10 \%$ of the known prevalence of the infection in dogs (12). Interestingly, autochthonous cases have recently been described in cats in the central (37) and southern regions of Italy (38) (Figure 1). On the other hand, it should be taken into account that the development of $D$. immitis in cats takes longer than in dogs, cats are generally amicrofilariaemic and clinical signs are generally transient, sometimes with sudden death $(11,12,35,39)$. Therefore, given that the diagnosis of $D$. immitis in cats is highly problematical, the infection is likely to be underestimated in feline patients from several territories where the parasite is endemic.

The life cycle and the dynamics and activity of the population of gastropods are also sensitive to temperature. At the same time, the development of nematode larvae in snails and slugs is known to be influenced by temperature changes. The Mediterranean Helix aspersa (Figure 2) edible snail is one of the most widely spread land snails in the world (40). Deliberately or accidentally imported, this species have recently become a pest outside its native Mediterranean range (41). Environmental temperatures may influence the biological cycle of the cat lungworm A. abstrusus and, in particular, the higher the average temperature the higher the rate of larval development in $H$. aspersa (15). In addition, larvae of $A$. abstrusus (and of T. brevior) may survive in overwintering H. aspersa (18). Given that the rise in temperatures has the potential to nurture the development of A. abstrusus, it is plausible that climate changes have contributed (and are contributing) to the apparent spreading of feline metastrongyloids in Europe. In fact, A. abstrusus has traditionally been considered sporadic in Europe but, recently, the parasite is constantly and increasingly reported in different areas of the continent (Table 1) suggesting that a possible expansion in 


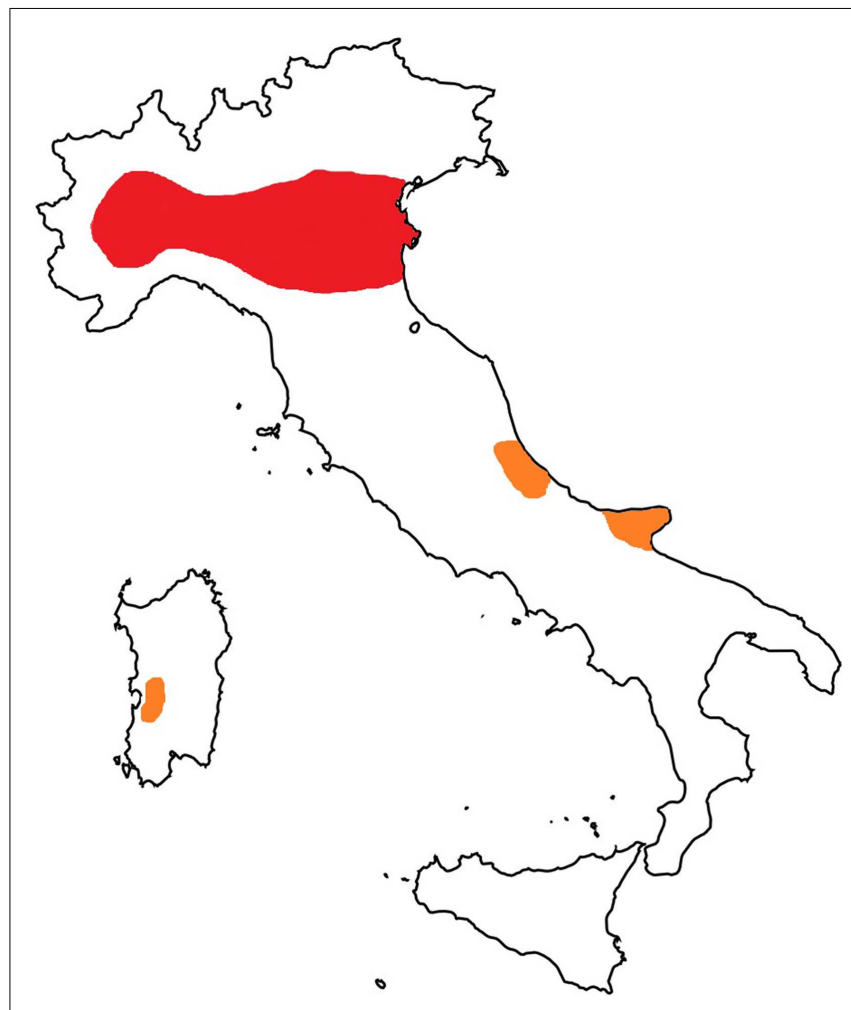

FIGURE 1 | Map of Italy: hyper-endemic area for Dirofilaria immitis (in red) and new autochthonous foci of infection in cats (in orange).

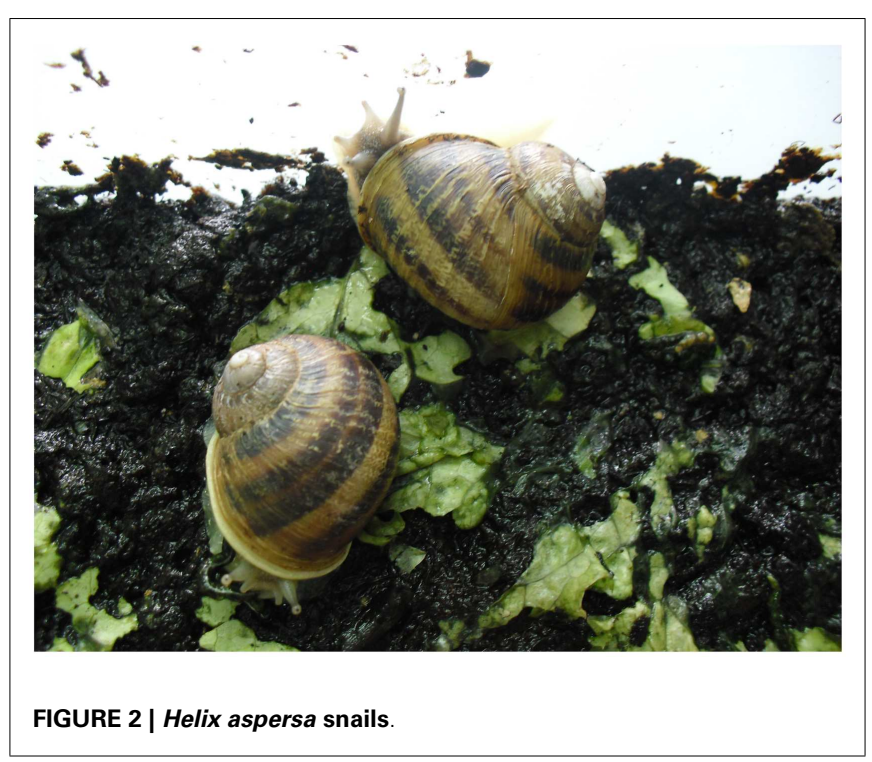

its geographical range and supporting a rise of prevalence in cats, with a rate of up to $25-50 \%(1,37,42-46)$.

Parasitic nematodes belonging to the genus Troglostrongylus have been regarded to infect only wild felids $(8,17,53)$. Nonetheless, the finding of T. brevior and Troglostrongylus subcrenatus in kittens on the islands of Ibiza and Sicily $(5,6)$ has renewed the scientific interest on these metastrongyloids (8). Troglostrongylus
Table 1 | Reported prevalence or clinical cases (S) of cat aelurostrongylosis in different European countries.

\begin{tabular}{lcl}
\hline Country & Aelurostrongylus abstrusus (\%) & Reference \\
\hline Albania & $39.7-50$ & $(44,45)$ \\
Belgium & $\mathrm{S}$ & $(1)$ \\
Croatia & $0.38-22$ & $(1)$ \\
Denmark & $\mathrm{S}$ & $(1)$ \\
France & $\mathrm{S}$ & $(1)$ \\
Germany & $0.5-15.3$ & $(47,48)$ \\
Great Britain & $3.6-10.6$ & $(49,50)$ \\
Greece & $\mathrm{S}$ & $(1)$ \\
Holland & 2.6 & $(1)$ \\
Hungary & 14.5 & $(51)$ \\
Ireland & $\mathrm{S}$ & $(1)$ \\
Italy & $1.8-24.4$ & $(1,43,52)$ \\
Norway & $\mathrm{S}$ & $(1)$ \\
Poland & $\mathrm{S}$ & $(1)$ \\
Portugal & 17.4 & $(42)$ \\
Romania & 5.6 & $(1)$ \\
Spain & 1 & $(1)$ \\
Turkey & $\mathrm{S}$ & $(1)$ \\
& &
\end{tabular}

brevior was described for the first time by Gerichter (17) and, since then, no other peer-reviewed international article has recorded the infection in domestic hosts. There is only a local report from Italy, which reported its occurrence in a wildcat and in a cat defined as "feral" in central Italy (54).

In the past few years, T. brevior has been recorded in other areas of Italy, i.e., in Sardinia Island and in southern and central continental territories $(7,9,10,46,55,56)$. The reasons for this present rise of descriptions are unknown. Given that different species of mollusks may transmit A. abstrusus and T. brevior $(17,18)$, changes in vector phenology nurtured by global warming might have a role in the present rise of cases for these cat lungworms. With specific regard to $T$. brevior, modifications in the life of wild reservoirs could be another cause of this apparent emergence (see below).

Feline infection by $C$. aerophila has often been considered sporadic and sub-clinical. However, the parasite has recently been described in cats in both clinical cases and during copromicroscopy-based surveys (9, 10, 52, 57-59), along with zoonotic infections in humans (60). The presence of C. aerophila is guaranteed by the high resistance of its eggs (Figure 3) even in harsh environmental conditions and by the ubiquity of earthworms, pending they actually intervene in the biological cycle of this worm. No thorough information is available on the impact of different temperature ranges in the maturation of C. aerophila eggs in the soil. However, a study has shown that eggs released by infected hosts start to develop after 35 days and mobile larvae are observed in the eggs after 2 months at $20 \pm 1^{\circ} \mathrm{C}$ and $80-85 \%$ of temperature and relative humidity (61). Further studies are necessary to understand whether different temperature values may change the speed and the rate of egg maturation on the environment. Therefore, at the moment it can only be argued that climate changes might partially influence the epidemiology of 


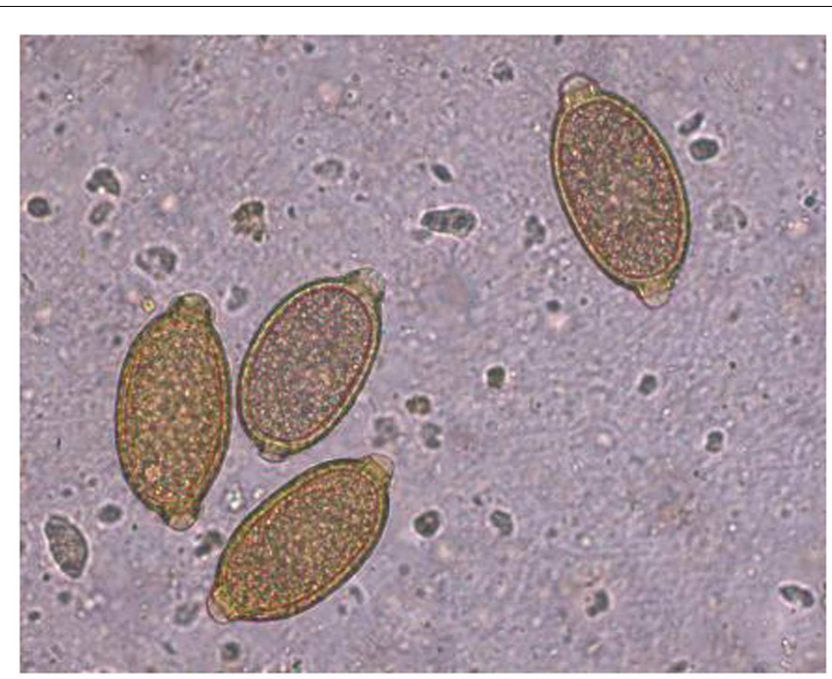

FIGURE 3 | Capillaria aerophila eggs

lung capillariosis, and that the occurrence (and spreading) of $C$. aerophila in cats may be due to other drivers (see below).

\section{VECTORS}

In the past decades, vectors and parasites have been introduced into European areas due to human intervention (e.g., urbanization), movements of people across countries, changes in the habitats of animals, the legal and illegal trade of animals and goods $(4,62)$.

The capability of commercial trade and movement of goods in favoring the introduction of competent vectors and the establishment of parasites from endemic regions to free areas has been demonstrated by the recent expansion of D. immitis (and Dirofilaria repens) in Europe. In fact, this phenomenon has somehow matched the introduction and spread of the Asian tiger mosquito Aedes albopictus (4). As a key example, the rapid distribution of $A$. albopictus throughout Italy has likely broadened the dirofilariosis range to previously free southern regions. Indeed, this mosquito may extend the animal (and human) risk of exposure to D. immitis for the day long and during the whole year in southern areas, especially in urban habitats. On the basis of retrospective evidence, it is clear that the expansion of dirofilariosis in Italy and Europe has followed the introduction and the spreading of $A$. albopictus in the continent by 1990 from Italy via commercial trades $(4,63)$.

In Italy, $D$. immitis and $D$. repens were found in natural populations of A. albopictus in 2000-2002 (64), and the rapid spread of this mosquito throughout the country has likely broadened the geographic range of dirofilariosis to southern regions not previously infected, despite C. p. pipiens had already established nationwide $(4,65)$. The geographic sympatrical occurrence in different European countries of A. albopictus and C. p. pipiens has become of great epidemiological relevance. Both mosquitoes have diurnal and nocturnal biting activities and may enhance the risk of infection to animals and humans in endemic areas throughout the day. In addition, C. p. pipiens has recently changed its endophagic and anthropophagic behavior in Central and North Europe, where it currently bites outdoors, as it was the case for southern parts of the continent $(4,66)$. The co-presence of both vectors could have promoted the risk of infection in central and southern regions of Italy (4) where new foci of dirofilariosis have been reported $(37,38)$. Interestingly, this pattern also overlaps with the spread of Dirofilaria spp. in central and north-eastern Europe (e.g., Switzerland, Czech Republic, Hungary, Serbia, and Slovak Republic) (2, 4, 26, 67-69).

Such changes might indeed have implications in the occurrence of $D$. immitis in cats. In fact, a study carried out in an $D$. immitis-endemic area, aiming at understanding the attraction of mosquitoes to domestic cats, has shown that Culex species were those most frequently found with feline blood meal, followed by Aedes species that also fed on feline blood. While Culex quinquefasciatus is mostly associated with cats infections $(39,70)$, also $A$. albopictus (and other closely related species) feed on feline blood and therefore they might be indeed involved in the transmission of D. immitis (71).

Analogously, the geographic spread of slugs and snails driven by conditions of global warming might play a role in the incidence and distribution of gastropod-transmitted parasites (7275). Among the different species of mollusks that transmit cat metastrongyloids, $H$. aspersa plays a major role in the biological cycle of lungworms. This land snail is now abundant in all anthropized areas of those regions with a climate suitable for its development (76) and, besides intentional introductions into previously free areas for farming purposes, it has also been accidentally introduced by the movement of plants and vegetables (41). The subsequently rapid adaptation of this snail to novel environmental conditions has partially been attributed to their ability in changing some of their life-history traits, such an increase in reproductive investment involving earlier maturity at a bigger size and a shorter generation time could thus explain its invasive success $(41,77)$. At the moment, $H$. aspersa is among the most common land snails in the world and it is also extensively farmed for human consumption in several countries (40). These snails are usually farmed in outdoor pens, which indeed may increase the risk for the biological interaction between snails, lungworms, and suitable felid hosts. Recently, infective A. abstrusus larvae have been found in the slug Arion lusitanicus in Poland (16). It is worth mentioning that $A$. lusitanicus is widespread and since the 1950s it has become established in many European countries, where it is now considered as a serious pest in agriculture and private gardens, parks, and forests (78). Indeed, A. lusitanicus has a high degree of plasticity in its thermal biology, it spreads rapidly in new geographical areas to which it has migrated and tends to occur in very high densities (79). The finding of A. abstrusus in this slug could represent a new potential source of infection for cats (16).

\section{WILDLIFE}

Current changes in phenology and biology of wildlife is a key driver in changing the epidemiology of internal and external parasites infecting companion animals, and this is also true for cardiopulmonary nematodes. In fact, wild animals are suitable reservoirs of poorly species-specific parasites which, in this particular case, may infect cats as well.

Destruction and/or reduction of natural habitats and conurbation have recently induced feral and wild felids and canids, 


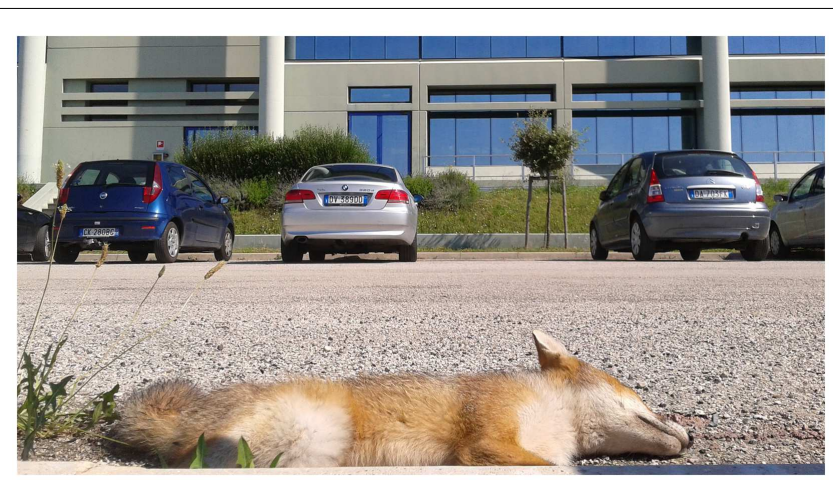

FIGURE 4 | Dead red fox in a peri-urban area of the municipality of Teramo, Abruzzo Region, Italy.

especially foxes, or even mustelids, to move into new hospitable environments and to look for anthropogenic food sources, e.g., the suburbs and cities. As a consequence, these movements favor the spread of wildlife parasites and increase the contact between parasites harbored in wildlife and pets (1, 80-82).

The presence of red foxes in cities and peri-urban areas (Figure 4) has been repeatedly evocated in concurring to the emergence of heartworms and lungworms in domestic hosts. Remarkably, red foxes are common reservoirs for D. immitis in European countries. Specifically, red foxes infected by D. immitis are present in Italy, Spain, Bulgaria, and Hungary, with a prevalent rate up to $32 \%(35,83-85)$. In accordance with the climate-based forecast prediction model, the prevalence and intensity of heartworm infection in wild canids in Hungary, which was not considered an endemic country until 2007, is similar to that observed in Mediterranean areas of Europe (85). Foxes infected by D. immitis in Hungary were not microfilariaemic, and no L1s were found in the uterus of the female worms recovered from necropsy, which were very few. The presence of a low number of adult nematodes without microfilariaemia could suggest that in some epidemiological settings, foxes are not adequate reservoirs for D. immitis (85, 86). However, microfilariemic foxes are present in Italy (84) and, outside Europe, in Australia (87), indicating that they are reservoirs of this nematode (4). As wild carnivores could be sentinels for the spread of D. immitis, the impact of foxes on the transmission dynamics of dirofilariosis and the reason of the different presence of microfilariae and adult worms in these hosts should be further investigated.

While red foxes could be a wild reservoir of the parasite in different epidemiological scenarios, other wild hosts found infected with $D$. immitis (e.g., wolves, jackals, otters, and ferrets), are likely to represent an epi-phenomenon for this infection (4).

The recent findings of T. brevior in domestic hosts are of difficult explanation. At the moment, it is hard to understand whether T. brevior (i) infects domestic cats in confined areas and/or under certain epidemiological settings; (ii) has been misdiagnosed as the more common A. abstrusus for a long time; (iii) is currently emerging in previously free areas and/or hosts due to a combination of climatic and biological factors. If one bears in mind that nematodes of Troglostrongylus genus have been traditionally considered proper of wild species of felids, the role of wildlife in causing the present cases of infections in domestic cats may possibly be attributed to wild reservoirs. Indeed, various information suggest that the occurrence of $T$. brevior in domestic cats could be due to a possible affiliation with this host mainly in certain regions or under conditions, which are particularly favorable for bridging infections between wild and domestic animals. It is possible that T. brevior could usually be confined in wild or feral hosts but able to change its usual affiliation under suitable epidemiological factors and routes of development and transmission that, at the same time, may spur the dispersion of A. abstrusus (8, Di Cesare et al., submitted).

Considering that the proper hosts of T. brevior are likely wild felids, the limited number of these animals even in their natural habitats might account for the marginal occurrence of this lungworm. Indeed, apart from the record from Ibiza Island, all reports of T. brevior are from Italy, where three subspecies of Felis spp. are present, i.e., the Sardinian wildcat Felis silvestris libyca, the European wildcat Felis silvestris silvestris, and the domestic cat Felis silvestris catus. These three Felis subspecies have a negligible level of hybridization, but recent demographic and ecological conditions have led to a certain degree of cross-breeding between wild and domestic cats (88). Moreover, some territories of Italy have faced an expansion in the geographical distribution of F. s. silvestris (89). It can be argued that some ecological and epidemiological drivers might recently have contributed in a spill-over of T. brevior from wild to domestic felids, in particular niches and under certain routes of transmission. This seems to be supported by the fact that T. brevior has been found exclusively where populations of F. s. silvestris and F. s. libyca may have the potential to come into contact with domestic cats. A recent retrospective work from endemic areas of Italy has evaluated the presence of lungworms in domestic cats, which received a diagnosis of respiratory parasitosis or with compatible lung lesions (Di Cesare et al., submitted). This study demonstrated that $A$. abstrusus was the major lungworm implicated in cat respiratory parasitosis in these regions of Italy in 2002-2013 and that T. brevior was present with low-infection rates (Di Cesare et al., submitted).

Recent data on the helminthofauna of F. s. silvestris in Italy showed that T. brevior is spread in wildcat populations of northern and southern Italy $(90,91)$. In particular, a high-infection rate $(71.4 \%)$ by $T$. brevior has been detected in wildcats from areas where this parasite has been described in some cats $(6,7$, 55).This evidence indicates that the infection is widespread among wild cats where appropriate ecological niches occur and that they could act as reservoir for this parasite (91). On the other hand, the high-infection rate in wild cats, in spite of occasional reports of troglostrongylosis in domestic cats from the same areas, indicates that F. s. silvestris is the natural host of T. brevior and may act as a spreader of the parasite. Indeed, the reduction of natural habitats may force wild and domestic cat to occupy the same habitats (92) and, as a consequence, a spill-over of T. brevior might occur from wild reservoirs to domestic hosts.

Capillaria aerophila infects a broad spectrum of animals, thus, lung capillariosis may occur in different species of wild and domestic carnivores. Although the infection in cats has often been considered sporadic, in the past decade, C. aerophila has been recorded 
in different countries $(47,51,52,57,59,93,94)$. It has recently been shown that distinct genetic populations of $C$. aerophila are shared between foxes, beech marten, cats, and dogs in European countries, supporting the existence of common patterns of transmission between wildlife and pets (20). Interestingly, 15 different haplotypes were characterized and 5 were shared between pets in Italy and wildlife in Europe with 3 genetic sub-populations infecting cats and foxes in Serbia, Romania, and Portugal. The existence of haplotypes shared between cats and wildlife in different countries suggests that common patterns of transmission for cardio-pulmonary nematodes could be of high epidemiological importance (20). It should also be borne in mind that $C$. aerophila may infect humans and that the most recent published case of human lung capillariosis has been reported in Serbia, where the infection rate of lung capillariosis in foxes is very high (60, 95). Importantly, the genetic haplotypes of $C$. aerophila found in Serbian foxes have also been described in cats (and dogs) in Italy and in foxes in Romania (20). Nonetheless, a comprehensive knowledge of the epidemiology of C. aerophila (e.g., range of hosts and geographic distribution) is still poor and it is difficult to assess to what degree this parasite may be spreading or what influence different factors may have on the current distribution of lung capillariosis.

\section{WHAT TO EXPECT IN THE NEAR FUTURE?}

An increased awareness is presently spurring new studies on felid heartworms and lungworms, and this could explain the rise of records of the infections they cause. These parasites have been regarded as occasional in cats for a long time, thus, lack of awareness and/or misdiagnosis could have resulted in an underestimation in the past. Indeed, $A$. abstrusus and C. aerophila may induce both sub-clinical and clinical infections, with varying clinical outcomes depending on different variables such as worm burden, age, and immune response of the infected animal, and concomitant diseases. Clinical signs, which are more severe in young, debilitated, and/or immunosuppressed animals, are common to many other respiratory diseases in cats (e.g., fungal, bacterial, and neoplastic diseases). Hence, cases of infection may be easily missed if appropriate laboratory methods are not applied by skillful operators $(8,96)$. For instance, although parasitological methods are able to detect $A$. abstrusus L1 and $C$. aerophila eggs, they are generally not performed by vet practitioners and suffer of diagnostic shortcomings, e.g., intermittent shedding of larvae and eggs (1).

\section{CARDIO-PULMONARY FILARIOSIS}

Cardio-pulmonary filariosis in cats may be characterized by a prolonged prodromal period with no apparent clinical signs, evolving in the sudden death of the animal $(97,98)$. When present, clinical signs are aspecific and the conventional diagnostic methods are unreliable to diagnose the disease in cats (98). In fact, the detection of circulating larvae in the bloodstream of cats is unlikely due to practically null and/or short-lasting periods of microfilariemia and to non-patent infections $(11,98)$. In the near future, ecological and biological drivers might indeed nurture the dispersion of $D$. immitis in cats, thus, veterinarians should be vigilant on possibly emerging feline dirofilariosis and improve their knowledge and awareness on diagnostic, control, and treatment methods.

\section{LUNGWORMS}

While adult animals harboring T. brevior are subclinically infected, clinical signs are severe in young animals and the infection is often fatal in kittens $(5-10,55,56,99)$. Indeed, the clinical severity of troglostrongylosis casts shadows on the hypothesis that $T$. brevior has been misdiagnosed in cats for a long time with the more common A. abstrusus. In fact, descriptions of severe or fatal aelurostrongylosis in literature are unusual, while the high level of pathogenicity of $T$. brevior, especially in kittens, makes it unlikely that these fatal cases in previous years were missed. Records of fatal infestations would have been more numerous if troglostrongylosis had so often been mistaken for aelurostrongylosis, and this is not the case (8). Therefore, it is plausible that some drivers are someway spurring the dispersion of the parasite in domestic hosts living in certain areas. Thus, if troglostrongylosis is a truly emerging parasitosis of cats, it could become an important threat in feline clinical practice in the near future.

These considerations mirror the recent scientific analysis carried out to explain the occurrence and the emergence of the high-pathogenic mollusk-borne nematode Angiostrongylus vasorum in dogs $(1,37,82,100,101)$. With similar life cycle patterns, the same drivers involved in the spread of $A$. vasorum would likely also have an effect on A. abstrusus, and possibly T. brevior. In fact, it can be argued that ecological factors are nurturing $T$. brevior infection in cats, at least in some regions, and that if these factors continue influencing the epidemiology of the disease, the nematode could expand its distribution in territories larger than the islands, southern and central areas of Italy (8). For instance, apart from climate change and the spreading of mollusks, another factor potentially promoting the emergence of cat troglostrongylosis is the possible spill-over of the nematode in those areas where populations of wild cats are living, i.e., the same regions where T. brevior has so far been recorded in domestic hosts (91, Di Cesare et al., submitted).

The infection by C. aerophila in cats is not commonly included in differential diagnosis in current practice and should be considered a neglected disease (1). Nevertheless, the clinical impact on feline patients, the increased awareness of its importance in veterinary practice, and the recent evidence of a spreading of this pathogen likely promoted by wild reservoirs would likely cause a rise of documented diagnosis in the near future. Veterinarians should become vigilant on this infection also because the parasite may infect different species of pets, and humans as well.

\section{CONCLUDING REMARKS}

In conclusion, evidence supports a present emergence of $D$. immitis, A. abstrusus, and C. aerophila, while several questions remain to be answered for T. brevior.

The further increment in temperatures expected in the future has the potential to expand areas of mosquito colonization, to favor the invasion of new areas and, possibly, to enhance their vectorial capability. Remarkably, a northward spread of the geographic occurrence of A. albopictus in western and central Europe up to the middle of the century has been assumed due to the general trend of increasing climatic suitability in regions that nowadays are unfavorable for this insect (102). This would also influence the 
rate of $D$. immitis infection in animals and people, the lengthening in the seasonal activity and the consequent rise in the biting rates received by susceptible hosts living in both traditional and new endemic areas. Although various mosquitoes (including C. p. pipiens) are more attracted to dogs than to cats $(39,70)$, the increase in density and their high adaptability in several territories, along with the presence of domestic (e.g., dogs) and wild (e.g., foxes) microfilariemic reservoirs, could increase the ability of $D$. immitis to establish transmission cycles and to also maintain the infection in feline populations.

With the present rise in temperatures, it can also be argued that the overwintering period of terrestrial mollusks will be shortened and that their seasonal activity will become longer. Hence, in the near future, cats with outdoor access would be more prone to be infected with lungworms.

Other than climatic variables, it should be elucidated on how and if other factors (e.g., wildlife movements, pet journeys) will further influence the current spread of these nematodes.

It is important to note that the lack of specificity of clinical signs of infections caused by cardio-pulmonary nematodes and the difficulties in the differential, clinical, and laboratory diagnosis may lead to misdiagnosis and/or missed diagnosis. Hence, animals have the potential to remain infected and untreated and, when they travel with their owners, various parasites may be transported from endemic to free regions.

If the emergence of these parasites is not only apparent but also a matter of fact, and if their dispersion continues to follow current trends, in the near future we could be faced with an increase of prevalence of feline heartworm disease and of lung capillariosis and aelurostrongylosis, along with cases of "new" infections, i.e., troglostrongylosis.

Under a practical standpoint, these potential changes would pose major clinical challenges in feline clinical practice. Veterinarians, parasitologists, and pet owners should be aware of the existence of cardio-parasitoses in cats and of the potential risk of introduction, establishment, and spreading of various nematodes, which might shortly alter the scenario of feline parasitology and clinical practice in a manner not easily foreseeable. This is particularly true in geographical regions considered free of infection and that has become or will become infected with "new parasites."

\section{AUTHOR CONTRIBUTIONS}

Donato Traversa conceived, drafted, and revised the manuscript. Angela Di Cesare contributed to conceiving and drafting the manuscript, and prepared sources of literature, figures, and tables. Both authors have approved the version to be published and agree to be accountable for all aspects of the work in ensuring that questions related to the accuracy or integrity of any part of the work are appropriately investigated and resolved.

\section{REFERENCES}

1. Traversa D, Di Cesare A, Conboy G. Canine and feline cardiopulmonary parasitic nematodes in Europe: emerging and underestimated. Parasit Vectors (2010) 3:62. doi:10.1186/1756-3305-3-62

2. Genchi C, Mortarino M, Rinaldi L, Cringoli G, Traldi G, Genchi M. Changing climate and changing vector-borne disease distribution: the example of
Dirofilaria in Europe. Vet Parasitol (2011) 176:295-9. doi:10.1016/j.vetpar. 2011.01.012

3. Simón F, Siles-Lucas M, Morchón R, González-Miguel J, Mellado I, Carretón E, et al. Human and animal dirofilariasis: the emergence of a zoonotic mosaic. Clin Microbiol Rev (2012) 7:507-44. doi:10.1128/CMR.00012-12

4. Otranto D, Dantas-Torres F, Brianti E, Traversa D, Petric D, Genchi C, et al. Vector-borne helminths of dogs and humans in Europe. Parasit Vectors (2013) 6:16. doi:10.1186/1756-3305-6-16

5. Jefferies R, Vrhovec MG, Wallner N, Catalan DR. Aelurostrongylus abstrusus and Troglostrongylus sp. (Nematoda: Metastrongyloidea) infections in cats inhabiting Ibiza, Spain. Vet Parasitol (2010) 173:344-8. doi:10.1016/j.vetpar. 2010.06.032

6. Brianti E, Gaglio G, Giannetto S, Annoscia G, Latrofa MS, Dantas-Torres F, et al. Troglostrongylus brevior and Troglostrongylus subcrenatus (Strongylida: Crenosomatidae) as agents of broncho-pulmonary infestation in domestic cats. Parasit Vectors (2012) 5:178. doi:10.1186/1756-3305-5-178

7. Brianti E, Gaglio G, Napoli E, Falsone L, Giannetto S, Latrofa MS, et al. Evidence for direct transmission of the cat lungworm Troglostrongylus brevior (Strongylida: Crenosomatidae). Parasitology (2013) 140:821-4. doi:10.1017/ S0031182013000188

8. Traversa D, Di Cesare A. Feline lungworms: what a dilemma. Trends Parasitol (2013) 29:423-30. doi:10.1016/j.pt.2013.07.004

9. Di Cesare A, Frangipane di Regalbono A, Tessarin C, Seghetti M, Iorio R, Simonato G, et al. Mixed infection by Aelurostrongylus abstrusus and Troglostrongylus brevior in kittens from the same litter in Italy. Parasitol Res (2014) 113:613-8. doi:10.1007/s00436-013-3690-y

10. Di Cesare A, Iorio R, Crisi P, Paoletti B, Di Costanzo R, Dimitri CF, et al. Treatment of Troglostrongylus brevior (Metastrongyloidea, Crenosomatidae) in mixed infections with other lungworms using spot-on emodepside. J Feline Med Surg (2014). doi:10.1177/1098612X14533552

11. McCall JW, Genchi C, Kramer LH, Guerrero J, Venco L. Heartworm disease in animals and humans. Adv Parasitol (2008) 66:193-285. doi:10.1016/S0065308X(08)00204-2

12. Venco L, Genchi M, Genchi C, Gatti D, Kramer L. Can heartworm prevalence in dogs be used as provisional data for assessing the prevalence of the infection in cats? Vet Parasitol (2011) 176:300-3. doi:10.1016/j.vetpar.2011.01.013

13. Anderson RC. Nematode Parasites of Vertebrates. Their Development and Transmission. Wallingford: CABI Publishing (2000).

14. Capelli G, Frangipane di Regalbono A, Simonato G, Cassini R, Cazzin S, Cancrini G, et al. Risk of canine and human exposure to Dirofilaria immitis infected mosquitoes in endemic areas of Italy. Parasit Vectors (2013) 6:60. doi:10.1186/1756-3305-6-60

15. Di Cesare A, Crisi PE, Di Giulio E, Veronesi F, Frangipane di Regalbono A, Talone T, et al. Larval development of the feline lungworm Aelurostrongylus abstrusus in Helix aspersa. Parasitol Res (2013) 112:3101-8. doi:10.1007/ s00436-013-3484-2

16. Jezewski W, Bunkowska-Gawlik K, Hildebrand J, Perec-Matysiak A, Laskowski Z. Intermediate and paratenic hosts in the life cycle of Aelurostrongylus abstrusus in natural environment. Vet Parasitol (2013) 198:401-5. doi:10.1016/ j.vetpar.2013.09.003

17. Gerichter CB. Studies on the nematodes parasitic in the lungs of felidae in Palestine. Parasitology (1949) 39:251-62.

18. Giannelli A, Ramos RA, Annoscia G, Di Cesare A, Colella V, Brianti E, et al. Development of the feline lungworms Aelurostrongylus abstrusus and Troglostrongylus brevior in Helix aspersa snails. Parasitology (2014) 141:563-9. doi:10.1017/S003118201300187X

19. Conboy G. Helminth parasite of the canine and feline respiratory tract. Vet Clin North Am Small Anim Pract (2009) 39:1109-26. doi:10.1016/j.cvsm.2009. 06.006

20. Di Cesare A, Otranto D, Latrofa MS, Veronesi F, Perrucci S, Lalosevic D, et al. Genetic variability of Eucoleus aerophilus from domestic and wild hosts. Res Vet Sci (2014) 96:512-5. doi:10.1016/j.rvsc.2014.03.018

21. Genchi C, Rinaldi L, Mortarino M, Genchi M, Cringoli G. Climate and Dirofilaria infection in Europe. Vet Parasitol (2009) 163:286-92. doi:10.1016/j.vetpar. 2009.03.026

22. Beugnet F, Chalvet-Monfray K. Impact of climate change in the epidemiology of vector-borne diseases in domestic carnivores. Comp Immunol Microbiol Infect Dis (2013) 36:559-66. doi:10.1016/j.cimid.2013.07.003 
23. Fortin JF, Slocombe JOD. Temperature requirements for the development of Dirofilaria immitis in Aedes triseriatus and Ae. Vexans Mosq. J Am Mosq Control Assoc (1981) 41:625-33.

24. Cancrini G, Pietrobelli M, Frangipane di Regalbono A, Tampieri MP, della Torre A. Development of Dirofilaria and Setaria nematodes in Aedes albopictus. Parassitologia (1995) 37:141-5.

25. Wilson N, Lush D, Baker MG. Meteorological and climate change themes at the 2010 international conference on emerging infectious diseases. Euro Surveill (2010) 15:19627.

26. Genchi C, Rinaldi L, Cascone C, Mortasino M, Cringoli G. Is heartworm disease really spreading in Europe? Vet Parasitol (2005) 133:137-48. doi:10.1016/ j.vetpar.2005.04.009

27. Slocombe JOD, Surgeoner GA, Srivastava B. Determination of the heartworm transmission period and its use in diagnosis and control. In: Otto GF, editor. Proceedings of the Heartworm Symposium'89. Washington: America Heartworm Society (1989). p. 19-26.

28. Knight DH, Lok JB. Seasonal timing of heartworm chemoprophylaxis in the United States. In: Soll MD, Knight DH, editors. Proceedings of Heartworm Symposium'92. Baravia, IL: American Heartworm Society (1995). p. 37-42.

29. Rinaldi L, Musella V, Marzatico G, Genchi C, Cringoli G. Geographical information systems in health application: experience on filariosis and other vectorborne diseases. In: Claerebout E, Vercruysse J, editors. Proceedings of the WAAVP Congress, August 19-23. Gent (2007). p. 165.

30. Jacsó O, Mándoki M, Majoros G, Pétsch M, Mortarino M, Genchi C, et al. First autochthonous Dirofilaria immitis (Leidy, 1856) infection in a dog in Hungary. Helminthologia (2009) 46:159-61. doi:10.2478/s11687-009-0030-y

31. Miterpáková M, Antolová D, Hurníková Z, Dubinský P, Pavlacka A, Németh J. Dirofilaria infections in working dogs in Slovakia. J Helminthol (2010) 84:173-6. doi:10.1017/S0022149X09990496

32. Swiatalska A, Demiaszkiewicz AW. First autochthonous case of Dirofilaria immitis invasion in dog in Poland. Žycie Weterynaryjne (2012) 7:685-6.

33. Kronefeld M, Kampen H, Sassnau R, Werner D. Molecular detection of Dirofilaria immitis, Dirofilaria repens and Setaria tundra in mosquitoes from Germany. Parasit Vectors (2014) 7:30. doi:10.1186/1756-3305-7-30

34. Genchi C, Bowman D, Drake J. Canine heartworm disease (Dirofilaria immitis) in Western Europe: survey of veterinary awareness and perceptions. Parasit Vectors (2014) 7:206. doi:10.1186/1756-3305-7-206

35. Morchón R, Carretón E, González-Miguel J, Mellado-Hernández I. Heartworm disease (Dirofilaria immitis) and their vectors in Europe - new distribution trends. Front Physiol (2012) 3:196. doi:10.3389/fphys.2012.00196

36. Kramer L, Genchi C. Feline heartworm infection: serological survey of asymptomatic cats living in northern Italy. Vet Parasitol (2002) 104:43-50. doi:10.1016/S0304-4017(01)00602-1

37. Traversa D, Aste G, Milillo P, Capelli G, Pampurini F, Tunesi C, et al. Autochthonous foci of canine and feline infections by Dirofilaria immitis and Dirofilaria repens in central Italy. Vet Parasitol (2010) 169:128-32. doi:10.1016/j.vetpar. 2009.12.034

38. Giangaspero A, Marangi M, Latrofa MS, Martinelli D, Traversa D, Otranto D, et al. Evidences of increasing risk of dirofilarioses in southern Italy. Parasitol Res (2013) 112:1357-61. doi:10.1007/s00436-012-3206-1

39. Genchi C, Di Sacco B, Cancrini G. Epizootiology of canine and feline heartworm infection in northern Italy: possible mosquito vectors. Proceedings of Heartworm Symposium '92. Austin, TX: American Heartworm Society (1992). p. 34-46.

40. Ansart A, Guiller A, Madec L. Invasive Species Compendium: Cornu aspersum. London: CABI (2009).

41. Guiller A, Martin MC, Hiraux C, Madec L. Tracing the invasion of the Mediterranean land snail Cornu aspersum aspersum becoming an agricultural and garden pest in areas recently introduced. PLoS ONE (2012) 7:e49674. doi:10.1371/journal.pone.0049674

42. Payo-Puente P, Botelho-Dinis M, Carvaja Urueña AM, Payo-Puente M, Gonzalo-Orden JM, Rojo-Vazquez FA. Prevalence study of the lungworm Aelurostrongylus abstrusus in stray cats of Portugal. J Feline Med Surg (2008) 10:242-6. doi:10.1016/j.jfms.2007.12.002

43. Traversa D, Di Cesare A, Milillo P, Iorio R, Otranto D. Aelurostrongylus abstrusus in a feline colony from central Italy: clinical features, diagnostic procedures and molecular characterization. Parasitol Res (2008) 103:1191-6. doi:10.1007/s00436-008-1115-0
44. Knaus M, Kusi I, Rapti D, Xhaxhiu D, Winter R, Visser M, et al. Endoparasites of cats from the Tirana area and the first report on Aelurostrongylus abstrusus (Railliet, 1898) in Albania. Wien Klin Wochenschr (2011) 123:31-5. doi:10.1007/s00508-011-1588-1

45. Knaus M, Rapti D, Shukullari E, Kusi I, Postoli R, Xhaxhiu D, et al. Characterisation of ecto- and endoparasites in domestic cats from Tirana, Albania. Parasitol Res (2014) 113:3361-71. doi:10.1007/s00436-014-3999-1

46. Tamponi C, Varcasia A, Brianti E, Pipia AP, Frau V, Pinna Parpaglia ML, et al. New insights on metastrongyloid lungworms infecting cats of Sardinia, Italy. Vet Parasitol (2014) 203:222-6. doi:10.1016/j.vetpar.2014.04.001

47. Barutzki D, Schaper R. Results of parasitological examinations of faecal samples from cats and dogs in Germany between 2003 and 2010. Parasitol Res (2011) 109:S45-60. doi:10.1007/s00436-011-2402-8

48. Barutzki D, Schaper R. Occurrence and regional distribution of Aelurostrongylus abstrusus in cats in Germany. Parasitol Res (2013) 112:855-61. doi:10.1007/ s00436-012-3207-0

49. Headley SA. Aelurostrongylus abstrusus induced pneumonia in cats: pathological and epidemiological findings of 38 cases (1987-1996). Semina: Ciências Agrárias (Londrina) (2005) 26:373-80.

50. Brickman K, Lewis R, Guitian J, Stevens K, Fox MT. Survey of Aelurostrongylus in cats in the UK - a comparison with Angiostrongylus in dogs. Proceedings of the World Association for the Advancement of Veterinary Parasitology, 25-29 August 2013. Perth (2013). p. 307.

51. Capári B, Hamel D, Visser M, Winter R, Pfister K, Rehbein S. Parasitic infections of domestic cats, Felis catus, in western Hungary. Vet Parasitol (2013) 192:33-42. doi:10.1016/j.vetpar.2012.11.011

52. Di Cesare A, Castagna G, Meloni S, Milillo P, Latrofa MS, Otranto D, et al. Canine and feline infections by cardiopulmonary nematodes in Central and Southern Italy. Parasitol Res (2011) 109:S87-96. doi:10.1007/s00436-0112405-5

53. Sarmiento L, Stough BD. Troglostrongylus wilsoni (Stough, 1953) n. comb. (Nematoda: Metastrongylidae) from the lungs of the bobcat, Lynx rufus rufus. Parasitology (1956) 42:45-8. doi:10.2307/3274620

54. Paggi L. Segnalazione, in Italia Centrale di Troglostrongylus sp. parassita dei polmoni di felidi. Parassitologia (1959) 1:80-1.

55. Giannelli A, Passantino G, Ramos RA, Lo Presti G, Lia RP, Brianti E, et al. Pathological and histological findings associated with the feline lungworm Troglostrongylus brevior. Vet Parasitol (2014) 204:416-9. doi:10.1016/j.vetpar. 2014.05.020

56. Traversa D, Romanucci M, Di Cesare A, Malatesta D, Cassini R, Iorio R, et al. Gross and histo-pathological changes associated with Aelurostrongylus abstrusus and Troglostrongylus brevior in a kitten. Vet Parasitol (2014) 201:158-62. doi:10.1016/j.vetpar.2014.01.020

57. Barrs VR, Martin P, Nicoll RG, Beatty JA, Malik R. Pulmonary cryptococcosis and Capillaria aerophila infection in an FIV-positive cat. Aust Vet J (2000) 78:154-8. doi:10.1111/j.1751-0813.2000.tb10581.x

58. Foster SF, Martin P, Allan GS, Barrs VR, Malik R. Lower respiratory tract infections in cats: 21 cases (1995-2000). J Feline Med Surg (2004) 6:167-80. doi:10.1016/j.jfms.2003.11.006

59. Traversa D, Di Cesare A, Milillo PM, Iorio R, Otranto D. Infection by Eucoleus aerophilus indogs and cats: is another extra-intestinal parasitic nematode of pets emerging in Italy? Res Vet Sci (2009) 87:270-2. doi:10.1016/j.rvsc.2009.02. 006

60. Lalosevic D, Lalosevic V, Klem I, Stanojev-Jovanovic D, Pozio E. Pulmonary capillariasis miming bronchial carcinoma. Am J Trop Med Hyg (2008) 78:14-6.

61. Traversa D, Di Cesare A, Lia RP, Castagna G, Meloni S, Heine J, et al. New insights into morphological and biological features of Capillaria aerophila (Trichocephalida, Trichuridae). Parasitol Res (2011) 109:S97-104. doi:10.1007/ s00436-011-2406-4

62. Colwell DD, Dantas-Torres F, Otranto D. Vector-borne parasitic zoonoses: emerging scenarios and new perspectives. Vet Parasitol (2010) 24:14-21. doi:10.1016/j.vetpar.2011.07.012

63. Sabatini A, Raineri V, Trovato G, Coluzzi M. Aedes albopictus in Italy and possible diffusion of the species into the Mediterranean area. Parassitologia (1990) 32:301-4.

64. Cancrini G, Frangipane di Regalbono A, Ricci I, Tessarin C, Gabrielli S, Pietrobelli M. Aedes albopictus is a natural vector of Dirofilaria immitis in Italy. Vet Parasitol (2003) 118:195-202. doi:10.1016/j.vetpar.2003.10.011 
65. Otranto D, Capelli G, Genchi C. Changing distribution patterns of canine vector borne diseases in Italy: leishmaniosis vs. dirofilariosis. Parasit Vectors (2009) 2:S2. doi:10.1186/1756-3305-2-S1-S2

66. Petric D, Zgomba M, Bellini R, Becker N. Surveillance of mosquito populations: a key element to understanding the spread of invasive vector species and vector-borne diseases in Europe. In: Mihailovic D, editor. Essays on Fundamental and Applied Environmental Topics. Hauppauge, NY: Nova Science Publishers (2012). p. 192-224.

67. Svobodova Z, Svobodova V, Genchi C, Forejtek P. The first report of autochthonous dirofilariosis in dogs in the Czech Republic. Helminthologia (2006) 43:242-5. doi:10.2478/s11687-006-0046-5

68. Babal P, Kobzova D, Novak I, Dubinsky P, Jalili N. First case of cutaneous human dirofilariosis in Slovak Republic. Bratisl Lek Listy (2008) 109:486-8.

69. Tasic A, Rossi L, Tasic S, Miladinovic-Tasic N, Ilic T, Dimitrijevic S. Survey of canine dirofilariasis in Vojvodina, Serbia. Parasitol Res (2008) 103:1297-302. doi:10.1007/s00436-008-1132-z

70. Labarthe N, Serrão ML, Melo YF, de Oliveira SJ, Lourenço-de-Oliveira R. Mosquito frequency and feeding habits in an enzootic canine dirofilariasis area in Niterói, state of Rio de Janeiro, Brazil. Mem Inst Oswaldo Cruz (1998) 93:145-54. doi:10.1590/S0074-02761998000200002

71. Gomes LA, Serrão ML, Duarte R, Bendas A, Labarthe N. Attraction of mosquitoes to domestic cats in a heartworm enzootic region. J Feline Med Surg (2007) 9:309-12. doi:10.1016/j.jfms.2007.01.009

72. Patz JA, Graczyk TK, Geller N, Vittor AY. Effects of environmental change on emerging parasitic diseases. Int J Parasitol (2000) 30:1395-405. doi:10.1016/ S0020-7519(00)00141-7

73. Prociv P, Carlisle MS. The spread of Angiostrongylus cantonensis in Australia, Southeast Asian. J Trop Med Public Health (2001) 32:126-8.

74. Macpherson CN. Human behaviour and the epidemiology of parasitic zoonoses. Int J Parasitol (2005) 35:1319-31. doi:10.1016/j.ijpara.2005.06.004

75. Tomlinson AJ, Taylor M, Roberts E. Angiostrongylus vasorum in canids. Vet Rec (2006) 159:60.

76. Guiller A, Madec L. Historical biogeography of the land snail Cornu aspersum: a new scenario inferred from haplotype distribution in the Western Mediterranean basin. BMC Evol Biol (2010) 10:18. doi:10.1186/1471-2148-10-18

77. Madec L, Desbuquois C, Coutellec-Vreto MA. Phenotypic plasticity in reproductive traits: importance in the life history of Helix aspersa (Mollusca: Helicidae) in a recently colonized habitat. Biol J Linn Soc Lond (2000) 69:25-39. doi:10.1111/j.1095-8312.2000.tb01667.x

78. Kozłowski J. The distribution, biology, population dynamics and harmfulness of Arion lusitanicus Mabile, 1868 (Gastropoda: Pulmonata: Arionidae) in Poland. J Plant Prot Res (2007) 47:219-30.

79. Slotsbo, S. Ecophysiology and Life History of the Slug, Arion lusitanicus. Ph.D. thesis, Aarhus University, Department of Agroecology, Denmark (2012). p. 80

80. Dryden MW, Brown S, Buck R, Schwahn T, Sloan S. Summers giving pets effective long-term protection against flea infestation. Vet Med (1998) 5:16-8.

81. Deplazes P, Hegglin D, Gloor S, Romig T. Wilderness in the city: the urbanization of Echinococcus multilocularis. Trends Parasitol (2004) 20:77-84. doi:10.1016/j.pt.2003.11.011

82. Morgan E, Shaw S. Angiostrongylus vasorum infection in dogs: continuing spread and developments in diagnosis and treatment. J Small Anim Pract (2010) 51:616-21. doi:10.1111/j.1748-5827.2010.01000.x

83. Gortazar C, Castillo JA, Lucientes J, Blanco JC, Arriolabengoa A, Calvete C. Factors affecting Dirofilaria immitis prevalence in red foxes in northeastern Spain. J Wildl Dis (1994) 30:545-7. doi:10.7589/0090-3558-30.4.545

84. Magi M, Calderini P, Gabrielli S, Dell'Omodarme M, Macchioni F, Prati MC, et al. Vulpes vulpes: a possible wild reservoir for zoonotic filariae. Vector Borne Zoonotic Dis (2008) 8:249-52. doi:10.1089/vbz.2007.0207

85. Tolnai Z, Széll Z, Sproch Á, Szeredi L, Sréter T. Dirofilaria immitis: an emerging parasite in dogs, red foxes and golden jackals in Hungary. Vet Parasitol (2014) 203:339-42. doi:10.1016/j.vetpar.2014.04.004

86. Marconcini A, Magi G, Macchioni G, Sassetti M. Filariosis in foxes in Italy. Vet Res Commun (1996) 20:316-9. doi:10.1007/BF00366537

87. Marks CA, Bloomfield TE. Canine heartworm (Dirofilaria immitis) detected in red foxes (Vulpes vulpes) in urban Melbourne. Vet Parasitol (1998) 78:147-54. doi:10.1016/S0304-4017(98)00131-9

88. Pierpaoli M, Birò ZS, Herrmann M, Hupe K, Fernandes M, Ragni B, et al. Genetic distinction of wildcat (Felis silvestris) populations in Europe, and hybridization with domestic cats in Hungary. Mol Ecol (2003) 12:2585-98. doi:10.1046/j.1365-294X.2003.01939.x

89. Lapini L. Attuale distribuzione del gatto selvatico Felis silvestris silvestris, Schreber, 1775 nell'Italia nord-orientale (Mammalia: Felidae). Bollettino del Museo civico di Storia Naturale di Venezia (2006) 57:221-34

90. Beraldo P, Massimo M, Pascotto E. Analysis of the helminthofauna of European wild cat in Friuli Venezia Giulia. In: Litografia La Ducale srl, editor. Proceedings of XXVIII Congresso Nazionale Società Italiana di Parassitologia. Rome (2014). p. 225.

91. Falsone L, Brianti E, Gaglio G, Napoli E, Anile S, Mallia E, et al. The European wildcats (Felis silvestris silvestris) as reservoir hosts of Troglostrongylus brevior (Strongylida: Crenosomatidae) lungworms. Vet Parasitol (2014) 205:193-8. doi:10.1016/j.vetpar.2014.06.024

92. Randi E, Pierpaoli M, Beaumont M, Ragni B, Sforzi A. Genetic identification of wild and domestic cats (Felis silvestris) and their hybrids using Bayesian clustering methods. Mol Biol Evol (2001) 18:1679-93. doi:10.1093/oxfordjournals. molbev.a003956

93. Miró G, Montoya A, Jiménez S, Frisuelos C, Mateo M, Fuentes I. Prevalence of antibodies to Toxoplasma gondii and intestinal parasites in stray, farm and household cats in Spain. Vet Parasitol (2004) 126:249-55. doi:10.1016/j.vetpar. 2004.08.015

94. Mircean V, Titilincu A, Vasile C. Prevalence of endoparasites in household cat (Felis catus) populations from Transylvania (Romania) and association with risk factors. Vet Parasitol (2010) 171:163-6. doi:10.1016/j.vetpar.2010.03.005

95. Laloševic V, Laloševic D, Capo I, Simin V, Galfi A, Traversa D. High infection rate of zoonotic Eucoleus aerophilus infection in foxes from Serbia. Parasite (2013) 20:3. doi:10.1051/parasite/2012003

96. Traversa D, Guglielmini C. Feline aelurostrongylosis and canine angiostrongylosis: a challenging diagnosis for two emerging verminous pneumonia infections. Vet Parasitol (2008) 157:163-74. doi:10.1016/j.vetpar.2008.07.020

97. Venco L, Genchi C, Genchi M, Grandi G, Kramer LH. Clinical evolution and radiographic findings of feline heartworm infection in asymptomatic cats. Vet Parasitol (2008) 158:232-7. doi:10.1016/j.vetpar.2008.09.011

98. Lee AC, Atkins CE. Understanding feline heartworm infection: disease, diagnosis, and treatment. Top Companion Anim Med (2010) 25:224-30. doi:10.1053/ j.tcam.2010.09.003

99. Brianti E, Giannetto S, Dantas-Torres F, Otranto D. Lungworms of the genus Troglostrongylus (Strongylida: Crenosomatidae): neglected parasites for domestic cats. Vet Parasitol (2014) 202:104-12. doi:10.1016/j.vetpar.2014. 01.019

100. Gallagher B, Brennan SF, Zarelli M, Mooney CT. Geographical, clinical, clinicopathological and radiographic features of canine angiostrongylosis in Irish dogs: a retrospective study. Ir Vet J (2012) 65:5. doi:10.1186/2046-0481-65-5

101. Mozzer LR, Lima WS. Rupture of the thoracic aorta associated with experimental Angiostrongylus vasorum infection in a dog. Parasite (2012) 19:189-91. doi:10.1051/parasite/2012192189

102. Fischer D, Thomas SM, Neteler M, Tjaden NB, Beierkuhnlein C. Climatic suitability of Aedes albopictus in Europe referring to climate change projections: comparison of mechanistic and correlative niche modeling approaches. Euro Surveill (2014) 19:20696.

Conflict of Interest Statement: The authors declare that the research was conducted in the absence of any commercial or financial relationships that could be construed as a potential conflict of interest.

Received: 29 July 2014; accepted: 11 September 2014; published online: 09 October 2014

Citation: Traversa D and Di Cesare A (2014) Cardio-pulmonary parasitic nematodes affecting cats in Europe: unraveling the past, depicting the present, and predicting the future. Front. Vet. Sci. 1:11. doi: 10.3389/fvets.2014.00011

This article was submitted to Parasitology, a section of the journal Frontiers in Veterinary Science.

Copyright (c) 2014 Traversa and Di Cesare. This is an open-access article distributed under the terms of the Creative Commons Attribution License (CC BY). The use, distribution or reproduction in other forums is permitted, provided the original author(s) or licensor are credited and that the original publication in this journal is cited, in accordance with accepted academic practice. No use, distribution or reproduction is permitted which does not comply with these terms. 